\title{
Is There Anything Better than Pt for HER?
}

Hansen, Johannes Novak; Prats, Hector; Toudahl, Karl Krøjer; Mørch Secher, Niklas; Chan, Karen; Kibsgaard, Jakob; Chorkendorff, lb

\section{Published in:}

ACS Energy Letters

Link to article, DOI:

10.1021/acsenergylett.1c00246

Publication date:

2021

Document Version

Publisher's PDF, also known as Version of record

Link back to DTU Orbit

Citation (APA):

Hansen, J. N., Prats, H., Toudahl, K. K., Mørch Secher, N., Chan, K., Kibsgaard, J., \& Chorkendorff, I. (2021). Is There Anything Better than Pt for HER? ACS Energy Letters, 6(4), 1175-1180.

https://doi.org/10.1021/acsenergylett.1c00246

\section{General rights}

Copyright and moral rights for the publications made accessible in the public portal are retained by the authors and/or other copyright owners and it is a condition of accessing publications that users recognise and abide by the legal requirements associated with these rights.

- Users may download and print one copy of any publication from the public portal for the purpose of private study or research.

- You may not further distribute the material or use it for any profit-making activity or commercial gain

- You may freely distribute the URL identifying the publication in the public portal

If you believe that this document breaches copyright please contact us providing details, and we will remove access to the work immediately and investigate your claim. 


\title{
E⿵⺆⿻二丨
}

\section{Is There Anything Better than Pt for HER?}

\author{
Johannes Novak Hansen, Hector Prats, Karl Krøjer Toudahl, Niklas Mørch Secher, Karen Chan, \\ Jakob Kibsgaard,* and Ib Chorkendorff*
}

Cite This: ACS Energy Lett. 2021, 6, 1175-1180

ABSTRACT: The search for cheap and abundant alternatives to Pt for the hydrogen evolution reaction (HER) has led to many efforts to develop new catalysts. Although the discovery of promising catalysts is often reported, none can compete with $\mathrm{Pt}$ in intrinsic activity. To enable true progress, a rigorous assessment of intrinsic catalytic activity is needed, in addition to minimizing mass-transport limitations and following best practices for measurements. Herein, we underline the importance of measuring intrinsic catalytic activities, e.g., turnover frequencies (TOFs). Using mass-selected, identical Pt nanoparticles at a range of loadings, we show the pervasive impact of mass-transport limitations on the observed activity of $\mathrm{Pt}$ in acid. We present the highest TOF measured for Pt at room temperature. Since our measurements are still limited by mass transport, the true intrinsic HER activity for $\mathrm{Pt}$ in acid is still unknown.

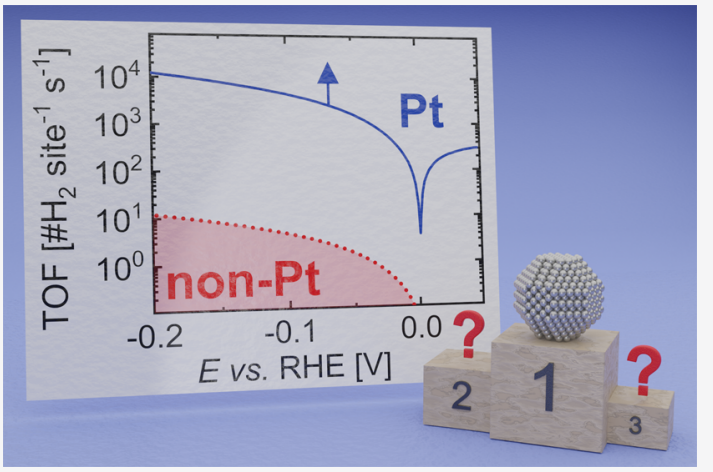
Using a numerical diffusion model, we suggest that hysteresis in cyclic voltammograms arises from $\mathrm{H}_{2}$ oversaturation, which is another indicator of mass-transport limitations.

$\mathrm{N}$ ovel hydrogen evolution reaction (HER) catalysts are often reported in the literature without regard for the applied catalyst loading, intrinsic activities, or possible mass-transport limitations. Much effort has been put into achieving high geometric current densities by increasing mass loading and the corresponding active surface area. ${ }^{1}$ However, the geometric current density, while important from the applied perspective, does not reflect the intrinsic catalytic activity that arises from tuning the electronic structure of the catalyst. The only metric of intrinsic activity is the turnover frequency (TOF), which is defined as the number of molecules (e.g., $\mathrm{H}_{2}$ ) produced per second per site. ${ }^{2}$ Furthermore, there are some common pitfalls which limit the quality and usefulness of the reported measurements in the literature, for instance: lacking potential scale calibration, lack of hydrogen saturation when performing HER, poor choice of counter electrode, and comparison to subpar measurements. ${ }^{1}$ Often, catalysts are claimed to have record-breaking activities or to surpass the performance of commercially available $\mathrm{Pt} / \mathrm{C}$. In general, a closer inspection shows this not to be the case, due to one or more of the aforementioned pitfalls. ${ }^{3-5}$

In this work, we study the influence of mass transport on the intrinsic Pt HER activity with rotating disk electrode (RDE) measurements and report benchmark values of the specific activities. We investigate identical, mass-selected $\mathrm{Pt}$ nanoparticles at a range of $\mathrm{Pt}$ loading as well as commercial $\mathrm{Pt} / \mathrm{C}$ samples, which together spans 4 orders of magnitude in $\mathrm{Pt}$ loading. We show that decreasing catalyst loading is effective in mitigating mass-transport limitations of HER (and HOR, the hydrogen oxidation reaction), but even at ultra-low loading, HER/HOR is mass-transport-limited on $\mathrm{Pt}$ in acid, and the resultant TOFs are only lower bounds on the intrinsic activity. By varying deposition area (using a small and a large raster pattern) of the mass-selected particles, we show that particle dispersion also influences TOF. To our knowledge, the TOF we report for the lowest Pt loading is the highest ever reported at room temperature regardless of the measurement technique. We furthermore find that the intrinsic activity of Pt exceeds that of any existing earth-abundant HER catalyst by at least 3 orders of magnitude. We also observe hysteresis in the cyclic voltammograms (CVs) at ultra-low Pt loadings, which we investigate using a time-dependent coupled kinetic-transport model. This model suggests that the displayed hysteresis is a marker for mass-transport limitations, since it arises from $\mathrm{H}_{2}$ buildup.

\section{WHY SITES MATTER}

We emphasize, first, that turnover frequencies are the only metric that reflects the intrinsic activity of a catalyst. Figure 1

Received: February 3, 2021

Accepted: March 3, 2021

Published: March 19, 2021 


\section{The intrinsic activity of Pt exceeds that of any existing earth-abundant HER catalyst by at least 3 orders of magnitude.}

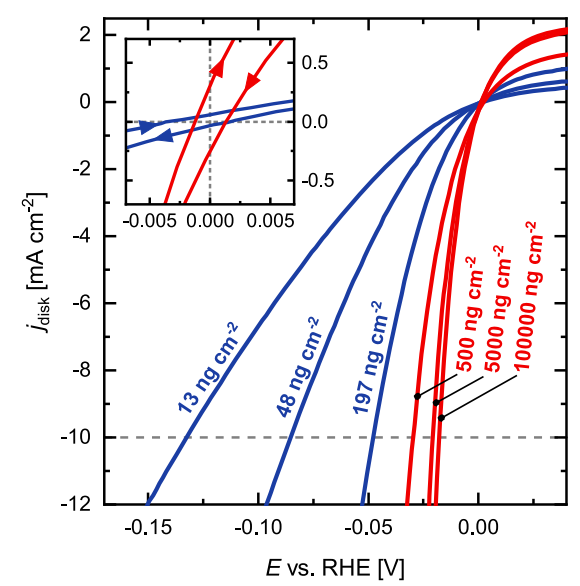

Figure 1. Cathodic sweeps of HER cyclic voltammograms for a representative set of $\mathrm{Pt}$ loadings exemplify how a lower overpotential to reach a certain geometric current density can be achieved by increasing catalyst loading. Blue lines correspond to $3.8 \mathrm{~nm} \mathrm{Pt}$ nanoparticles deposited with the cluster source over a small raster pattern, while red lines correspond to commercially available $\mathrm{Pt} / \mathrm{C}$ catalyst. Note that for $3.8 \mathrm{~nm}$ nanoparticles, $j_{\text {disk }}$ is a lower bound on the real geometric current density, since the raster pattern area is smaller than the disk. (Inset) Anodic and cathodic sweeps for the lowest- and highest-loading samples are shown. Correct calibration ensures the $\mathrm{CV}$ passes $(0,0)$ at low scan speeds or with a negligible spread to each side at higher scan speeds. It is necessary to calibrate the reference electrode vs RHE and maintain a completely $\mathrm{H}_{2}$-saturated electrolyte throughout any HER/HOR experiment used for measuring catalytic activity. Failing to do so results in an ill-defined potential shift and consequently an invalid activity measurement. ${ }^{9}$ CVs were recorded in $\mathrm{H}_{2}$-saturated $0.5 \mathrm{M}$ $\mathrm{H}_{2} \mathrm{SO}_{4}$ with a rotation rate of $\omega=1600 \mathrm{rpm}$ and are post-corrected for $100 \%$ of the ohmic drop as measured by EIS. A potential scan rate of $\nu=50 \mathrm{mV} \mathrm{s}{ }^{-1}$ was used for all samples except for the two highest loadings (50 000 (not shown in Figure) and $100000 \mathrm{ng}$ $\mathrm{cm}^{-2}$ ), in which case $10 \mathrm{mV} \mathrm{s}^{-1}$ was used to minimize the influence of double-layer charging current arising from the relative high roughness.

shows the geometric current densities normalized by disk area $\left(j_{\text {disk }}\right)$ for a representative subset of samples of $\mathrm{Pt}$ loading from 13 to $10^{5} \mathrm{ng} \mathrm{cm}^{-2}$. The overpotential $\left(\eta_{10} \mathrm{~mA} \mathrm{~cm}^{-2}\right)$ needed to reach a geometric current density of $10 \mathrm{~mA} \mathrm{~cm}{ }^{-2}$ is often reported in literature without consideration for the catalyst loading. ${ }^{5-8}$ From Figure 1, it is obvious that the overpotential needed to reach a certain current density can be reduced simply by increasing the catalyst loading and hence the number of active sites. This is not equivalent to improved intrinsic catalytic activity. Between the lowest loading and the highest loading, 13 and $10^{5} \mathrm{ng} \mathrm{cm}^{-2}$, respectively, $\eta_{10} \mathrm{~mA} \mathrm{~cm}^{-2}$ varies by more than $0.1 \mathrm{~V}$, and it is therefore apparent why considering the active site density is crucial for any meaningful comparison of intrinsic activity.

The TOF should be reported whenever possible, as it is the relevant scientific metric for comparing intrinsic activity. Without the site density, $j_{\text {ECSA }}$ (ECSA: electrochemically active surface area) may be used as an approximation of the TOF. If
The turnover frequency should be reported whenever possible, as it is the relevant scientific metric for comparing intrinsic activity.

neither metric is available, the mass activity $\left(j_{\text {mass }}\right)$ can be used as a stand-in metric for activity. While $j_{\text {mass }}$ is by default not indicative of intrinsic activity, it can have some merit as a techno-economic metric, since the catalyst material is priced by mass. Considering this, it is only meaningful to replace platinum with a high mass loading of a catalyst of lower mass activity, if the catalyst price (e.g., $\$ \mathrm{mg}^{-1}$ ) is correspondingly lower than that of platinum. The HER mass activity of platinum is several orders of magnitude higher than those of phosphide-based catalysts reported in the literature. ${ }^{1}$ This may significantly limit the feasibility of simply increasing mass loading of abundant catalysts. As a benchmark for comparison of mass activity, $j_{\text {mass }}$ versus $\eta_{10} \mathrm{~mA} \mathrm{~cm}$ cm $^{-2}$ is plotted for all loadings considered in Figure $\mathrm{S} 3$ in the Supporting Information (SI). Although $j_{\text {geo }}$ can be useful from the practical perspective of the activity of a large-scale electrolyzer or photoelectochemical device, it is not useful in the comparison of intrinsic catalytic activity from a scientific point of view.

\section{TRANSPORT LIMITATIONS ARE UBIQUITOUS IN RDE MEASUREMENTS OF Pt IN ACID}

Figure $2 \mathrm{~A}$ shows the corresponding TOFs at $-15 \mathrm{mV}$ overpotential for all samples. While the $j_{\text {disk }}$ increases with loading, the TOF decreases by 3 orders of magnitude. This dramatic reduction in TOF with increasing loading indicates that mass-transport limitations play a major role for all samples, as will be discussed in the following. Akin to what is observed for the mass activity, Figure 2A shows that highly dispersed $3.8 \mathrm{~nm}$ nanoparticles (green) also perform slightly better than their less dispersed counterparts (blue). It can be ruled out that the effect stems solely from the less dispersed samples suffering more from particle overlap and hence a loss in ECSA, since the activity metric is normalized per site. It is also worth noting that, although loss of ECSA at higher loadings is to be expected, the effect is moderate even at 5000 $\mathrm{ng} \mathrm{cm} \mathrm{cm}^{-2}$ (see Figure S2 for further details).

$\mathrm{RDE}$ experiments offer enhanced mass transport compared to electrodes submerged in an unstirred solution. ${ }^{10}$ Even so, the kinetics of acidic HOR/HER on Pt are so facile that the measured currents in RDEs with Pt disk electrodes are entirely limited by mass transport of $\mathrm{H}_{2}$ to (HOR) or away from (HER) the electrode. ${ }^{9,11-13}$ Under these conditions, the intrinsic activity has no effect on the measured activity, and the frequently reported Tafel slope of $30 \mathrm{mV} / \mathrm{dec}$ for HER is just the apparent Tafel slope of the diffusion overpotential at room temperature. ${ }^{9}$ From Figure $2 \mathrm{~A}$ it is evident that, even in the limit of ultra-low Pt loading, the mass-transport limitation dominates, since no plateau for the TOF is reached. Similarly, less active non-Pt catalysts might also be affected by slow mass transport when loading is sufficiently high. Mass-transport limitations therefore prevent a genuine comparison of intrinsic activities. A common pitfall is to report and compare a catalyst to a reference measurement (typically $\mathrm{Pt} / \mathrm{C}$ ) of significantly higher loading. ${ }^{4}$ Given the mass-transport limitation of $\mathrm{Pt}$, the higher the loading applied, the lower the TOF (or $j_{\text {mass }}$ ) observed. The reported catalyst thus seems more active than 


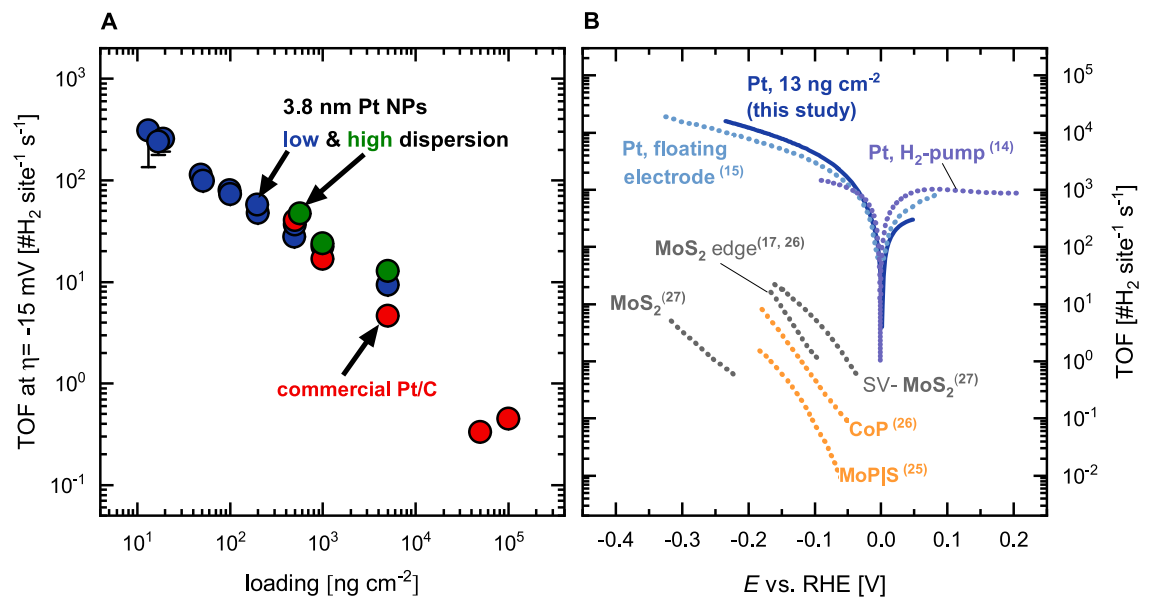

Figure 2. (A) TOF at $\eta=-15 \mathrm{mV}$ vs Pt loading for all samples in the present study. Blue and green dots correspond to $3.8 \mathrm{~nm} \mathrm{Pt}$ nanoparticles deposited over a glassy carbon disk using small and large raster areas, respectively, while red dots correspond to commercially available $\mathrm{Pt} / \mathrm{C}$ catalyst. The turnover frequency is calculated using the $\mathrm{CO}$-strip charge of each sample, and all error bars are within the size of the markers except for the three lowest loadings $\left(13,17\right.$, and $19 \mathrm{ng} \mathrm{cm}^{-2}$ ) as displayed. (B) TOFs corresponding to the cathodic scans for the lowest-loading sample in this study (solid blue line) and other $\mathrm{Pt} / \mathrm{C}$ samples using fast mass-transport techniques: floating electrode (dotted light blue line) and $\mathrm{H}_{2}$-pump (dotted purple line) taken from refs 15 and,14, respectively. A selection of transition metal sulfides and phosphides are added for comparison: MoPIS, ${ }^{25} \mathrm{CoP},{ }^{26} \mathrm{MoS}_{2}($ edge $),{ }^{17,26}$ and $\left(\mathrm{MoS}_{2}, \mathrm{SV}-\mathrm{MoS}_{2}\right) .{ }^{27}$ See section 4 in the SI for further details.

the reference measurement, leading to a false conclusion (see Figure $\mathrm{S} 4$ as an example).

Figure 2B compares the TOF for the lowest-loading sample in this study (i.e., $13 \mathrm{ng} \mathrm{cm}^{-2}$ ) with the TOFs reported for other Pt samples using fast mass-transport techniques (i.e., $\mathrm{H}_{2}$ pump method ${ }^{14}$ and floating electrodes ${ }^{15}$ ). Note that our lowest-loading sample, along with the floating electrode technique of the Kucernak group, ${ }^{15}$ gives the highest HER activity reported for $\mathrm{Pt}$ at room temperature. This result, along with the trend shown in Figure 2A, shows that decreasing the loading is a general strategy to evaluate and mitigate the impact of mass-transport effects in electrochemical reactions. However, since the TOF does not reach an obvious upper limit with decreasing loading, the lowest-loading sample gives a lower bound on HER activity. Therefore, the HER measurements using fast mass-transport techniques are most likely also limited by mass transport and thus do not display the true intrinsic activity. We find, from the micropolarization region, an apparent exchange current density of $j_{0}=140 \mathrm{~mA} \mathrm{~cm}_{\mathrm{Pt}}{ }^{-2}$ at room temperature (see section 5.2 in the $\mathrm{SI}$ ), almost twice the value $\left(j_{0}=75 \mathrm{~mA} \mathrm{~cm}_{\mathrm{Pt}}{ }^{-2}\right)$ reported from $\mathrm{H}_{2}$-pump measurements. ${ }^{14}$

\section{Decreasing the loading is a general strategy to evaluate and mitigate the impact of mass-transport effects in electrochemical reactions.}

Over the past decade, metal sulfides ${ }^{16-19}$ and, more recently, metal phosphides ${ }^{20-22}$ have proven to be active HER catalysts. The development of these classes of catalysts has been inspired by biomimicry and known catalysts for the hydrodesulfurization (HDS) process. ${ }^{16,17}$ The hydrogen adsorption free energy $\left(\Delta G_{\mathrm{H}}\right)$ has proven to be a good descriptor for rationalizing the measured activities of these catalysts, ${ }^{16,23}$ which follow a volcano-like trend where $\Delta G_{\mathrm{H}} \approx 0$ corresponds to the highest activity. Apart from $\mathrm{Pt}$, metal sulfides and phosphides are located at the top of the volcano. However, as shown in Figure
2B, their intrinsic activities are at least 3 orders of magnitude lower for comparable room-temperature measurements. Thus, $\Delta G_{\mathrm{H}} \approx 0$ is not a sufficient predictor for intrinsic catalytic activity. Kinetic barriers or coverage effects could be at play; these effects should be explored if alternative catalysts, which can compete with platinum on intrinsic activity, are to be developed. $^{22,24}$

\section{HYSTERESIS IN POLARIZATION CURVES ARISES FROM $\mathrm{H}_{2}$ BUILDUP}

Apart from the variation in specific activity with the loading, another indication that the measured currents are limited by mass transport is the presence of hysteresis in the HER branch. As shown in Figure 3A, the activity is higher in the cathodic scan than in the subsequent anodic-going scan (see also Figure S5). We evaluate this effect using a time-dependent numerical model that couples reaction kinetics and diffusion of $\mathrm{H}^{+}$and $\mathrm{H}_{2}$, as detailed in section 5 in the SI. To validate the model, we benchmarked it against the data in ref 9, where the polarization curves for HOR/HER on a full-sized Pt disk in $0.1 \mathrm{M} \mathrm{HClO}_{4}$ at different rotation rates (i.e., ranging from 100 to $3600 \mathrm{rpm}$ ) were reported to have varying degrees of hysteresis. As shown in Figure S9, simulated and experimental polarization curves are in nearly quantitative agreement. We furthermore include a parametric study in section 5.4 in the SI, which shows that the degree of hysteresis depends on the relative rate of mass transport determined by the rotation rate, the diffusion coefficients, and the scan rate.

The conditions of the present study are slightly more complex. The same scan rate (i.e., $50 \mathrm{mV} \mathrm{s}^{-1}$ ) and rotation rate (i.e., $1600 \mathrm{rpm}$ ) are used to record the CVs. However, the loading is varied, and the low-loading samples are scanned to more negative potentials and present lower geometric current densities and more hysteresis. This trend may seem contradictory to the reaction being completely mass-transportcontrolled and can be attributed to a slowdown in the effective diffusion coefficients in the HER branch at the lowest loadings, as shown in Figure 3B,C. Assuming uniform diffusion coefficients for all samples (i.e., valid in dilute solutions), the 


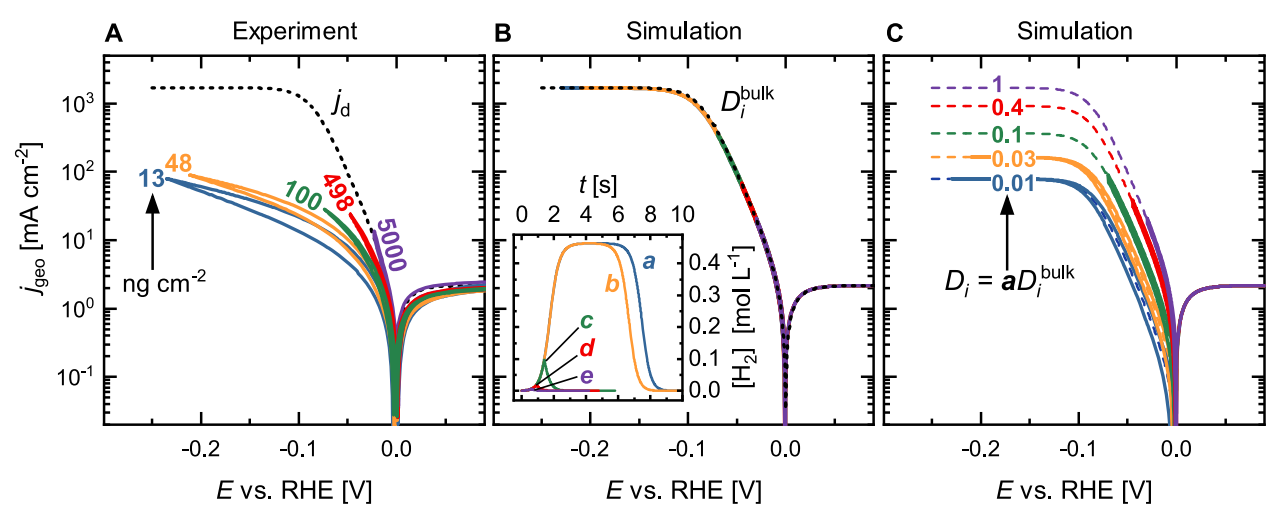

Figure 3. (A) iR-corrected polarization curves for $\mathrm{HOR} / \mathrm{HER}$ on $3.8 \mathrm{~nm} \mathrm{Pt}$ nanoparticles in $\mathrm{H}_{2}$-saturated $0.5 \mathrm{M} \mathrm{H}_{2} \mathrm{SO}_{4}$ at a scan rate of 50 $\mathrm{mV} \mathrm{s}{ }^{-1}$, a rotation rate of $1600 \mathrm{rpm}$, and different loadings: $13 \mathrm{ng} \mathrm{cm}^{-2}$ (blue), $48 \mathrm{ng} \mathrm{cm}^{-2}$ (orange), $100 \mathrm{ng} \mathrm{cm}^{-2}$ (green), $498 \mathrm{ng} \mathrm{cm}$

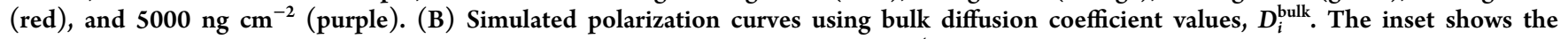
average surface concentration of $\mathrm{H}_{2}$ as a function of time during the simulation (traces $a-e$ correspond to 13, 48, 100, 498, and 5000 ng $\mathrm{cm}^{-2}$, respectively). (C) Simulated polarization curves (solid lines) using scaled diffusion coefficients $a D_{i}^{\text {bulk }}$ with $a \leq 1$. Dashed lines are the concentration overpotential curves for scaled diffusion coefficients, and $a=1$ (purple) corresponds to bulk diffusion coefficients.

model predicts CVs for the different samples to all follow the concentration overpotential curve (black dashed line; discussed in section 6 in the SI). This curve corresponds to the Nernstian limit where the intrinsic kinetics play no role in the current density. However, the model reproduces qualitatively the experimental trends if the diffusion coefficients of $\mathrm{H}_{2}$ and $\mathrm{H}^{+}$for low-loading samples in the HER branch are scaled by a factor $0 \leq 1$, as shown in Figure 3C.

We hypothesize the drastic reduction in the rate of mass transport at the interface to arise from a large, local $\mathrm{H}_{2}$ buildup at the lowest loadings. The inset in Figure $3 \mathrm{~B}$ suggests that the $\mathrm{H}_{2}$ oversaturation in the HER branch can be larger than 400 $\mathrm{mmol} \mathrm{L}-1$ in the lowest-loading samples that are swept to the most negative potentials (more details in section 6 in the SI and Figure S16). This corresponds to an increase of up to 3 orders of magnitude with respect to saturation concentration at room temperature (i.e., $\left.0.59 \mathrm{mmol} \mathrm{L}^{-1}\right){ }^{28}$ For the lowestloading samples, we expect this buildup to be more localized than suggested by the present mean-field model, since they operate at a much higher TOF and have a much lower active area (Figure $2 \mathrm{~A}$ ). This high buildup of evolved $\mathrm{H}_{2}$ might lead to partial hindrance of incoming $\mathrm{H}^{+}$and outgoing $\mathrm{H}_{2}$ species, as well as to the formation of $\mathrm{H}_{2}$ microbubbles, 13,29 that remain located on the catalyst surface, blocking active sites; both of these effects could lead to a reduction in the diffusion rate. We note that the formation of microbubbles at geometric current densities higher than 2-4 $\mathrm{mA} \mathrm{cm} \mathrm{cm}^{-2}$ has been suggested, ${ }^{13,29}$ and as shown in Figure 3A, the geometric current densities recorded in this study for low-loading samples can reach $100 \mathrm{~mA} \mathrm{~cm}^{-2}$. Our simple scaling approach does not account for the changes in diffusion coefficient with the changes in the concentration of $\mathrm{H}_{2}$ buildup as the potential is swept; to our knowledge, there is no established relationship between diffusion coefficient and $\mathrm{H}_{2}$ concentration. This is presumably why the experimental CVs show a smoother transition as the potential is swept, whereas the simulations have the down-scaled diffusion constant artificially imposed from the onset. The present scaling factors serve to heuristically illustrate the impact of a change in diffusion coefficient on the degree of hysteresis. Using a power-law function to describe the variation of the diffusion coefficients with $\mathrm{H}_{2}$ concentration leads to a better agreement with the experimental CVs, albeit sacrificing simplicity (see Figure S12).

\section{OPPORTUNITIES AND CHALLENGES}

In summary, the mass-transport limitations of HER in acid make the assessment of true intrinsic activity of $\mathrm{Pt}$ an open challenge. Since we observe mass-transport limitations even at ultra-low Pt loading, but with an activity which is on par with fast mass-transport techniques, we conclude that the intrinsic activity of $\mathrm{Pt}$ is still underestimated. The presented activity may well be the highest ever reported at room temperature, but it remains only a lower bound estimate.

\section{The intrinsic activity of Pt is still underestimated.}

We suggest that decreasing loading is a general strategy to evaluate and mitigate the influence of mass-transport effects in electrochemical reactions. For highly active catalysts, the combination of fast mass-transport techniques and ultra-low catalyst loading might be particularly useful. By combining experiments and numerical modeling, we illustrate that the presence of hysteresis in HER CVs at ultra-low catalyst loading is a further marker of mass-transport limitations. Observing similar phenomena in other setups and reactions could possibly help to identify relevant mass-transport limitations.

So is there anything better than Pt for HER? To our knowledge, no earth-abundant catalyst material comes even close to Pt in terms of intrinsic activity. Any claim of making a better catalyst should be supported by a rigorous characterization of intrinsic activity (TOF), with careful consideration of the impact of mass-transport limitations.

\section{ASSOCIATED CONTENT}

\section{Supporting Information}

The Supporting Information is available free of charge at https://pubs.acs.org/doi/10.1021/acsenergylett.1c00246.

Description of electrochemical methods, sample preparation (nanoparticle deposition and drop casting), general experimental procedures, additional experimental results, characterization (STEM and ISS), description of numerical simulation model, benchmarking of model, parametric study, and further discussion, including Figures S1-S16 and Tables S1-S13 (PDF) 


\section{AUTHOR INFORMATION}

\section{Corresponding Authors}

Jakob Kibsgaard - SurfCat, Department of Physics, Technical University of Denmark, 2800 Kongens Lyngby, Denmark; ๑ orcid.org/0000-0002-9219-816X; Email: jkib@ fysik.dtu.dk

Ib Chorkendorff - SurfCat, Department of Physics, Technical University of Denmark, 2800 Kongens Lyngby, Denmark; ๑ orcid.org/0000-0003-2738-0325; Email: ibchork@ fysik.dtu.dk

\section{Authors}

Johannes Novak Hansen - SurfCat, Department of Physics, Technical University of Denmark, 2800 Kongens Lyngby, Denmark; $\odot$ orcid.org/0000-0003-0142-3112

Hector Prats - CatTheory, Department of Physics, Technical University of Denmark, 2800 Kongens Lyngby, Denmark; ๑ orcid.org/0000-0003-4991-253X

Karl Krøjer Toudahl - SurfCat, Department of Physics, Technical University of Denmark, 2800 Kongens Lyngby, Denmark

Niklas Morch Secher - SurfCat, Department of Physics, Technical University of Denmark, 2800 Kongens Lyngby, Denmark

Karen Chan - CatTheory, Department of Physics, Technical University of Denmark, 2800 Kongens Lyngby, Denmark; (- orcid.org/0000-0002-6897-1108

Complete contact information is available at:

https://pubs.acs.org/10.1021/acsenergylett.1c00246

\section{Notes}

The authors declare no competing financial interest.

\section{Biographies}

Johannes Novak Hansen is currently a Ph.D. student in the SurfCat group, supervised by Ib Chorkendorff and Jakob Kibsgaard. He has B.Sc. and M.Sc. degrees in physics and nanotechnology from the Technical University of Denmark. His research interest is within electro-catalysis and its application for the sustainable synthesis of fuels and chemicals.

Hector Prats completed his doctoral studies in 2019 at the University of Barcelona. At present, he is a postdoctoral researcher at CatTheory, Technical University of Denmark, under the supervision of Dr. Karen Chan. His current research interest lies in understanding hydrogen redox reactions on the atomic scale.

Karl Krøjer Toudahl holds B.Sc. (2017) and a M.Sc. (2019) degrees in physics and nanotechnology from the Technical University of Denmark and is currently a Ph.D. student under the supervision of Professor Ib Chorkendorff and Associate Professor Jakob Kibsgaard. His research is focused on the synthesis and characterization of atomic clusters and nanoparticles, primarily for electrocatalytic reactions.

Niklas Mørch Secher received his Ph.D. in surface science and experimental catalysis from the Technical University of Denmark in 2020. He has specialized in synthesis and characterization of welldefined model catalysts for investigating the fundamentals of catalytic reactions. His work focuses on catalysis for reactions in sustainable energy technologies such as HER, ORR, and OER.

Karen Chan is an Associate Professor at the Technical University of Denmark at the CatTheory Center in the Department of Physics. Her research focuses on computational electrochemistry toward a sustainable carbon cycle. She was previously an Associate Staff
Scientist at SUNCAT as part of the Joint Center for Artificial Photosynthesis.

Jakob Kibsgaard is an Associate Professor of Physics at the Technical University of Denmark. He received his Ph.D. from Aarhus University in 2008. His research focuses on the development and understanding of thermal and electro-catalysts for sustainable energy conversion. He is currently a Carlsberg Foundation Distinguished Fellow and ERC consolidator grantee.

Ib Chorkendorff is a Professor in heterogeneous catalysis at the Technical University of Denmark (DTU)-Physics. He has authored or co-authored more than 370 scientific papers, 22 patents, and one textbook. His research activities focus on finding new catalysts for improving energy production/conversion and for environmental protection. $\mathrm{He}$ is co-founder of three start-up companies.

\section{ACKNOWLEDGMENTS}

For funding of this work, we gratefully acknowledge the European Research Council (ERC) under the European Union's Horizon 2020 research and innovation program (CLUNATRA, Advanced Grant, PE4, ERC-2016-ADG), the Villum Foundation through grant no. 9455, and the Carlsberg Foundation grant CF18-0435. Finally, we thank Bingjun Xu for supplying the data ${ }^{9}$ used in Figure S9, and we also thank Julien Durst and Hubert Gasteiger for supplying the $\mathrm{H}_{2}$-pump data ${ }^{14}$ used in Figure 2B.

\section{REFERENCES}

(1) Kibsgaard, J.; Chorkendorff, I. Considerations for the Scaling-up of Water Splitting Catalysts. Nat. Energy 2019, 4 (6), 430-433.

(2) Boudart, M. Turnover Rates in Heterogeneous Catalysis. Chem. Rev. 1995, 95 (3), 661-666.

(3) Cheng, N.; Stambula, S.; Wang, D.; Banis, M. N.; Liu, J.; Riese, A.; Xiao, B.; Li, R.; Sham, T. K.; Liu, L. M.; Botton, G. A.; Sun, X. Platinum Single-Atom and Cluster Catalysis of the Hydrogen Evolution Reaction. Nat. Commun. 2016, 7 (1), 13638.

(4) Zhang, L.; Si, R.; Liu, H.; Chen, N.; Wang, Q.; Adair, K.; Wang, Z.; Chen, J.; Song, Z.; Li, J.; Banis, M. N.; Li, R.; Sham, T.-K.; Gu, M.; Liu, L.-M.; Botton, G. A.; Sun, X. Atomic Layer Deposited Pt-Ru Dual-Metal Dimers and Identifying Their Active Sites for Hydrogen Evolution Reaction. Nat. Commun. 2019, 10 (1), 4936.

(5) Qu, Y.; Shao, M.; Shao, Y.; Yang, M.; Xu, J.; Kwok, C. T.; Shi, X.; Lu, Z.; Pan, H. Ultra-High Electrocatalytic Activity of VS2 Nanoflowers for Efficient Hydrogen Evolution Reaction. J. Mater. Chem. A 2017, 5 (29), 15080-15086.

(6) Cao, L.; Luo, Q.; Liu, W.; Lin, Y.; Liu, X.; Cao, Y.; Zhang, W.; Wu, Y.; Yang, J.; Yao, T.; Wei, S. Identification of Single-Atom Active Sites in Carbon-Based Cobalt Catalysts during Electrocatalytic Hydrogen Evolution. Nat. Catal. 2019, 2 (2), 134-141.

(7) Zhang, J.; Zhang, C.; Wang, Z.; Zhu, J.; Wen, Z.; Zhao, X.; Zhang, X.; Xu, J.; Lu, Z. Synergistic Interlayer and Defect Engineering in VS 2 Nanosheets toward Efficient Electrocatalytic Hydrogen Evolution Reaction. Small 2018, 14 (9), 1703098.

(8) Li, Z.; Fu, J. Y.; Feng, Y.; Dong, C. K.; Liu, H.; Du, X. W. A Silver Catalyst Activated by Stacking Faults for the Hydrogen Evolution Reaction. Nat. Catal. 2019, 2, 1107-1114.

(9) Zheng, J.; Yan, Y.; Xu, B. Correcting the Hydrogen Diffusion Limitation in Rotating Disk Electrode Measurements of Hydrogen Evolution Reaction Kinetics. J. Electrochem. Soc. 2015, 162 (14) F1470-F1481.

(10) Levich, V. G. Physicochemical Hydrodynamics; Prentice-Hall: Englewood Cliffs, NJ, 1962.

(11) Zalitis, C. M.; Kramer, D.; Kucernak, A. R. Electrocatalytic Performance of Fuel Cell Reactions at Low Catalyst Loading and High Mass Transport. Phys. Chem. Chem. Phys. 2013, 15 (12), 43294340 . 
(12) Kucernak, A. R.; Zalitis, C. General Models for the Electrochemical Hydrogen Oxidation and Hydrogen Evolution Reactions: Theoretical Derivation and Experimental Results under Near Mass-Transport Free Conditions. J. Phys. Chem. C 2016, 120 (20), 10721-10745.

(13) Sheng, W.; Gasteiger, H. A.; Shao-Horn, Y. Hydrogen Oxidation and Evolution Reaction Kinetics on Platinum: Acid vs Alkaline Electrolytes. J. Electrochem. Soc. 2010, 157 (11), 1529-1536.

(14) Durst, J.; Simon, C.; Hasche, F.; Gasteiger, H. A. Hydrogen Oxidation and Evolution Reaction Kinetics on Carbon Supported Pt, $\mathrm{Ir}, \mathrm{Rh}$, and Pd Electrocatalysts in Acidic Media. J. Electrochem. Soc. 2015, 162 (1), F190-F203.

(15) Zalitis, C. M.; Kramer, D.; Sharman, J.; Wright, E.; Kucernak, A. R. Pt Nano-Particle Performance for PEFC Reactions at Low Catalyst Loading and High Reactant Mass Transport. ECS Trans. 2013, 58 (1), 39-47.

(16) Hinnemann, B.; Moses, P. G.; Bonde, J.; Jørgensen, K. P.; Nielsen, J. H.; Horch, S.; Chorkendorff, I.; Nørskov, J. K. Biomimetic Hydrogen Evolution: MoS2 Nanoparticles as Catalyst for Hydrogen Evolution. J. Am. Chem. Soc. 2005, 127 (15), 5308-5309.

(17) Jaramillo, T. F.; Jørgensen, K. P.; Bonde, J.; Nielsen, J. H.; Horch, S.; Chorkendorff, I. Identification of Active Edge Sites for Electrochemical H2 Evolution from MoS2 Nanocatalysts. Science (Washington, DC, U. S.) 2007, 317 (5834), 100-102.

(18) Kibsgaard, J.; Jaramillo, T. F.; Besenbacher, F. Building an Appropriate Active-Site Motif into a Hydrogen-Evolution Catalyst with Thiomolybdate [Mo3S13]2- Clusters. Nat. Chem. 2014, 6 (3), 248-253.

(19) Kibsgaard, J.; Chen, Z.; Reinecke, B. N.; Jaramillo, T. F. Engineering the Surface Structure of MoS2 to Preferentially Expose Active Edge Sites for Electrocatalysis. Nat. Mater. 2012, 11 (11), 963-969.

(20) Popczun, E. J.; McKone, J. R.; Read, C. G.; Biacchi, A. J.; Wiltrout, A. M.; Lewis, N. S.; Schaak, R. E. Nanostructured Nickel Phosphide as an Electrocatalyst for the Hydrogen Evolution Reaction. J. Am. Chem. Soc. 2013, 135 (25), 9267-9270.

(21) Popczun, E. J.; Read, C. G.; Roske, C. W.; Lewis, N. S.; Schaak, R. E. Highly Active Electrocatalysis of the Hydrogen Evolution Reaction by Cobalt Phosphide Nanoparticles. Angew. Chem. 2014, 126 (21), 5531-5534.

(22) Kibsgaard, J.; Tsai, C.; Chan, K.; Benck, J. D.; Nørskov, J. K.; Abild-Pedersen, F.; Jaramillo, T. F. Designing an Improved Transition Metal Phosphide Catalyst for Hydrogen Evolution Using Experimental and Theoretical Trends. Energy Environ. Sci. 2015, 8 (10), $3022-3029$.

(23) Nørskov, J. K.; Bligaard, T.; Logadottir, A.; Kitchin, J. R.; Chen, J. G.; Pandelov, S.; Stimming, U. Trends in the Exchange Current for Hydrogen Evolution. J. Electrochem. Soc. 2005, 152 (3), J23.

(24) Seh, Z. W.; Kibsgaard, J.; Dickens, C. F.; Chorkendorff, I.; Nørskov, J. K.; Jaramillo, T. F. Combining Theory and Experiment in Electrocatalysis: Insights into Materials Design. Science 2017, 355 (6321), eaad4998.

(25) Kibsgaard, J.; Jaramillo, T. F. Molybdenum Phosphosulfide: An Active, Acid-Stable, Earth- Abundant Catalyst for the Hydrogen Evolution Reaction. Angew. Chem., Int. Ed. 2014, 53 (52), 1443314437.

(26) Hellstern, T. R.; Benck, J. D.; Kibsgaard, J.; Hahn, C.; Jaramillo, T. F. Engineering Cobalt Phosphide (CoP) Thin Film Catalysts for Enhanced Hydrogen Evolution Activity on Silicon Photocathodes. Adv. Energy Mater. 2016, 6 (4), 1501758.

(27) Li, H.; Tsai, C.; Koh, A. L.; Cai, L.; Contryman, A. W.; Fragapane, A. H.; Zhao, J.; Han, H. S.; Manoharan, H. C.; AbildPedersen, F.; Nørskov, J. K.; Zheng, X. Erratum: Activating and Optimizing MoS2 Basal Planes for Hydrogen Evolution through the Formation of Strained Sulphur Vacancies. Nat. Mater. 2016, 15, 4853; Nat. Mater. 2016, 15 (3), 364.

(28) Mello, R. M. Q.; Ticianelli, E. A. Kinetic Study of the Hydrogen Oxidation Reaction on Platinum and Nafion@ Covered Platinum Electrodes. Electrochim. Acta 1997, 42 (6), 1031-1039.
(29) Rheinländer, P. J.; Herranz, J.; Durst, J.; Gasteiger, H. A. Kinetics of the Hydrogen Oxidation/Evolution Reaction on Polycrystalline Platinum in Alkaline Electrolyte Reaction Order with Respect to Hydrogen Pressure. J. Electrochem. Soc. 2014, 161 (14), F1448-F1457. 